\section{LA-UR-02-0977}

Approved for public release; distribution is unlimited.
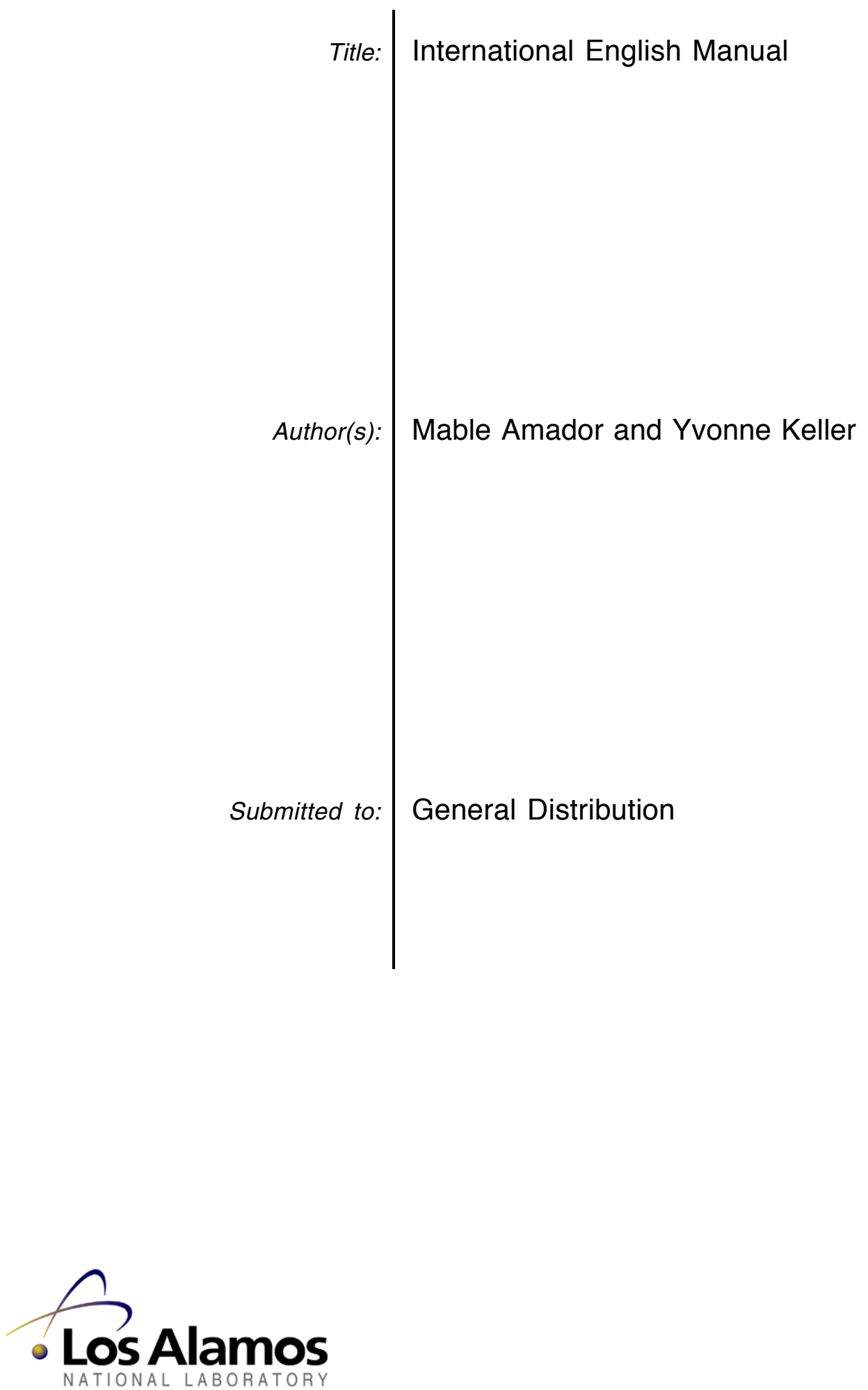

Los Alamos National Laboratory, an affirmative action/equal opportunity employer, is operated by the University of California for the U.S. Department of Energy under contract W-7405-ENG-36. By acceptance of this article, the publisher recognizes that the U.S. Government retains a nonexclusive, royaltyfree license to publish or reproduce the published form of this contribution, or to allow others to do so, for U.S. Government purposes. Los Alamos National Laboratory requests that the publisher identify this article as work performed under the auspices of the U.S. Department of Energy. Los Alamos National Laboratory strongly supports academic freedom and a researcher's right to publish; as an institution, however, the Laboratory does not endorse the viewpoint of a publication or guarantee its technical correctness. 


\section{TABLE OF CONTENTS}

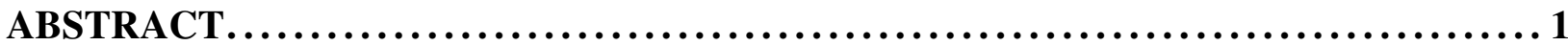

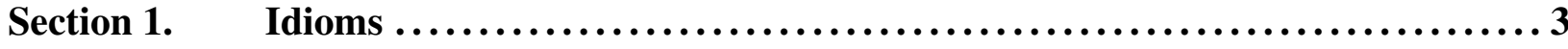

Section 2. Technical Terms (One Meaning per Word) $\ldots \ldots \ldots \ldots \ldots \ldots \ldots \ldots \ldots \ldots 7$

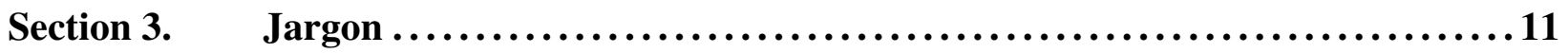

Section 4. Acronyms, Initialisms, and Abbreviations $\ldots \ldots \ldots \ldots \ldots \ldots \ldots \ldots \ldots \ldots \ldots$

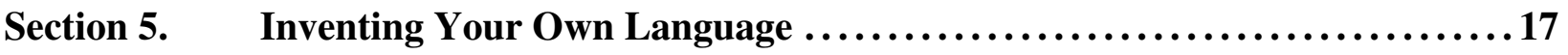

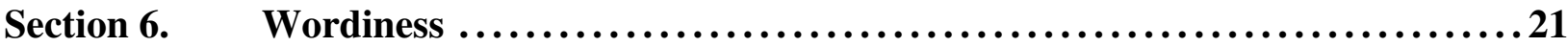

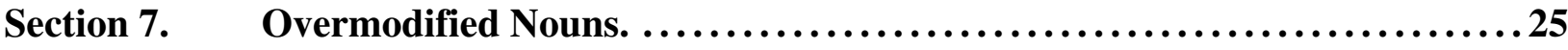

Section 8. The Apostrophe Form of the Possessive Case $\ldots \ldots \ldots \ldots \ldots \ldots \ldots \ldots \ldots \ldots 27$

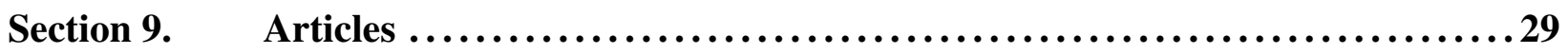

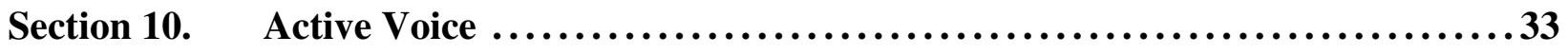

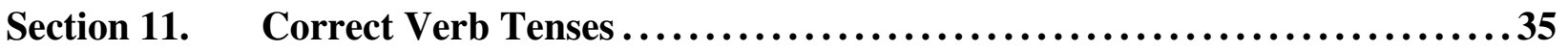

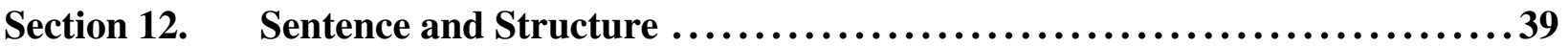

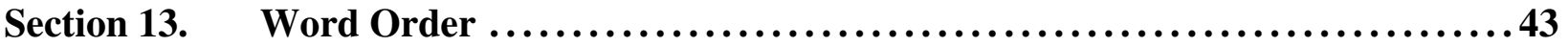

Section 14. Ellipses....................................................45

Section 15. Nonrestrictive and Introductory Elements $\ldots \ldots \ldots \ldots \ldots \ldots \ldots \ldots \ldots \ldots \ldots 1$

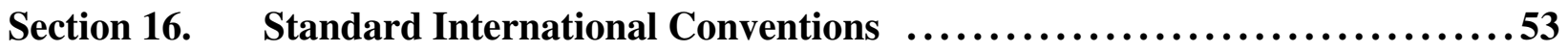

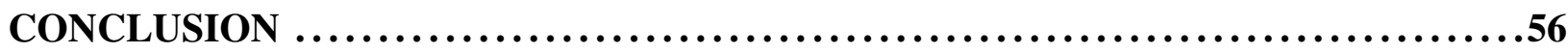

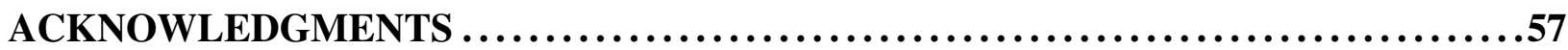

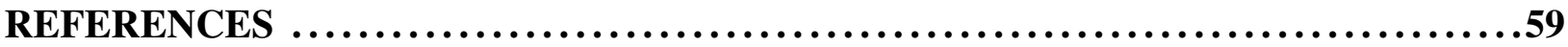





\title{
INTERNATIONAL ENGLISH MANUAL
}

by

Mable Amador and Yvonne Keller

\begin{abstract}
This document presents a set of guidelines for authors who wish to express themselves more clearly to foreign readers, or readers whose first language is not American English. Topics include idioms, technical terms, jargon, word meaning, acronyms, and international conventions of measurement. The guidelines will help writers of technical documents present their ideas more effectively to audiences that may include individuals whose first language is not American English, including audiences with individuals from other English-speaking countries.
\end{abstract}




\section{Section 1. Idioms}

An idiom is an expression that assumes a new meaning-different from the "sum" of the meanings of the individual words - when it is used in a context different from the one in which it originally developed.

Guideline: To enhance understanding or your presentation or document, it is best to avoid idioms and localized expressions.

Idioms and localized expressions can add richness to a sentence, but they are hard for foreign readers to understand. In fact, idioms and localized expressions can prevent part of your audience from understanding at all. People whose first language is not English, individuals from other English-speaking countries, and younger individuals who have grown up in a different "time and place" may not understand the meaning of a catchy idiom or localized expression.

\section{Examples}

The sentence

"He never got to first base with the experiment,"

if understood literally (as in the game of baseball), would mean that the individual was unable to run from home plate to first base carrying an experiment.

The actual meaning of "He never got to first base with the experiment" is that "He was unable to make even the first part of the experiment work."

Idiomatic expressions probably exist in every language. In fact, according to $A$ Dictionary of American Idioms ${ }^{1}$ there are no known languages that do not have some idioms. It is likely that idioms arise from our desire to find ever more colorful or humorous ways to express ideas.

\section{Jargon}

There is sometimes a fine line between idiomatic usage and jargon. Like an idiom, jargon is an expression or term applied to a context different from the one in which it originated; jargon possesses its peculiar meaning only when it is used in the context in which that peculiar meaning arose (for example, "being online"-meaning the act of working on a computer-has that meaning only in the field of computers).

\section{Idioms}

An idiom may be applied to many fields other than the one in which it originated, and it will always have the same meaning.

\section{Examples of idioms}

"The successful repair of the space telescope was a shot in the arm for NASA." 
"The late-season storm caused extensive damage, but this proved to be a shot in the arm for the local economy."

"New data became available just in time to provide a needed shot in the arm to the cold fusion project."

When hearing or reading an English idiom for the first time, individuals from nonEnglish cultural and linguistic traditions will most likely understand it in its nonidiomatic sense (its literal meaning). Some idioms are relatively easy to figure out. Others are not.

For foreign readers, most idioms are almost impossible to figure out. For example,

"Most of this work was done on a shoestring."

"Because the electromagnetic environment is quite different, it might be difficult to build systems flexible enough to be effective across the board."

"LANL developed and implemented a pressure control algorithm, along with a number of bells and whistles."

\section{How idioms are developed}

As a society develops new technologies and approaches to problem solving, new idioms are sure to follow. The idiom in the following example would have been incomprehensible before the days of steam power:

"While Vitamin E lost some of its steam during the study, Vitamin C was still effective after 24 hours."

In similar fashion, the rapid spread of computer technology is beginning to affect language:

"The water sampling system developed for this program proved to be more user-friendly than we expected."

\section{Localized expressions}

Related to idioms are localized expressions. They too are associated with particular cultures. Would the British understand the following sentence from an American paper?

"Detroit has been especially hard hit by the economic downturn."

This example illustrates that, through long association with particular professions or industries, place names can actually become surrogates for those professions or industries (Detroit means the automobile industry).

Other localized terms and expressions are those that develop within an organization and are meaningful only to members of that organization. At the Los Alamos National Laboratory, some widely used acronyms have become so familiar that they have turned into words. The acronym RIF (reduction in force), for which perhaps every other organization uses the term "layoff," is now freely used as a verb: "He was riffed last month." 
It is not unheard of that localized expressions creep into documents and presentations slated for foreign consumption. For example, American businessmen may ask foreign colleagues for "ballpark" figures, inform them that the cost will be 600 "K," or advise them that more "R\&D" will be needed—all usages "local" to American culture. (Code: ballpark figure means approximate amount, 600K means 600,000 , and R\&D means research and development.)

Authors of localized expressions often do not "think twice" about whether their audience will be able to grasp the meaning. We recommend thinking twice and avoiding localized expressions in presentations intended for international audiences.

The following examples contain localized expressions and idioms.

1. We will meet at the "Y" before continuing our inspection of outlying sites.

2. At least six different groups had a finger in this pie.

3. The international JOWOG meeting will be held at the Forum located in the building accessed by the "Kentucky Fried Chicken" guard station.

4. Like a Dagwood sandwich, the project began to reach unmanageable dimensions.

5. The Industrial Business Development Program Office is located near the "ice house."

6. When initial attempts to recalibrate the system failed, we decided to take another tack.

7. Cost-benefit analysis must recognize and deal with this diversity to avoid strawman arguments.

8. Failure to recognize the downsides of this approach can lead us to sink our own ship.

9. If you think mass transportation is going to replace the automobile, I think you're whistling Dixie. (Henry Ford II)

10. S-Site is the location of our new offices.

\section{Answers}

1. We will meet at the intersection of Highway 502 and State Road 4 below the town of Los Alamos before continuing our inspection of outlying sites.

2. At least six different groups have an interest in this project.

3. The international JOWOG meeting will be held at the Forum located in the building to the east of the Study Center at Los Alamos National Laboratory.

4. The project grew in complexity until it began to reach unmanageable dimensions.

5. The Industrial Business Development Program Office is located near Ashley Pond next to the Fuller Lodge. (The Ice House was used to store ice in the summer before electricity and electric refrigerators were available.) 
6. When initial attempts to recalibrate the system failed, we decided to use other techniques.

7. Cost-benefit analysis must recognize and deal with this diversity to avoid arguments that can easily be defeated.

8. Failure to recognize the negative aspects of this approach can lead us to failure.

9. If you think mass transportation is going to replace the automobile, I think you're being unrealistic.

10. Our new offices are in the technical areas west of the main Laboratory buildings called collectively S-Site. 


\section{Section 2. Technical Terms (One Meaning per Word)}

In technical writing, using the same term to describe the same item throughout the entire document will help the reader understand.

\section{Using two different terms to mean the same thing: two different names for the same item}

In poetry and in essays, using different terms throughout will increase the magic and aesthetic nature of the work. Referring to the "babbling brook" and the "meandering stream" as the same object is acceptable in poetry. But in technical writing, and in writing for foreign audiences, two terms for the same item are confusing.

\section{Using the same term to describe two different things: the same technical term with two different meanings}

When writing for foreign readers or writing a document that is to be translated, using the same technical term to describe two different items can also cause confusion.

The following joke was being circulated a few years ago.

\section{Subject: DOE Labs called to action.}

"I learned today that the new Secretary of Energy issued an executive Action Memorandum to four national laboratories. The text of the directive consisted of a single word: JUMP!"

LAWRENCE LIVERMORE replied, "Please supply particulars as to the desired number of people to jump, and to the desired elevation and direction (azimuth and declination). We will forward a safety plan and an environmental impact statement. Upon receiving your concurrence, we will provide jumpers with bells, whistles, and balloons to ensure a truly outstanding demonstration of jumping."

LOS ALAMOS replied, "To heck with you. We only do good science here. However, we conjecture that there could be nonlinear effects no yet considered in jumping that might lead to qualitatively different behavior than any previously seen. As a result, we will study the issue."

LAWRENCE BERKELEY replied, "In accordance with your directive we will host an international symposium on jumping, with experts from the U.S. and 35 foreign countries. Your assistance will be appreciated in obtaining travel support, visa approvals, and foreign visitor security clearances."

SANDIA replied, "YES SIR. Saluted, immediately took a jumping posture, and then requested $20 \%$ of the other Laboratories' budgets to develop a plan to lead the other Laboratories."

The underlined words show the possibilities of misunderstanding the text. "To jump" may mean to "attack" as well as to leap into space. The second usage could mean a costume or a person leaping into space. The other examples explain the term as leaping into space. Of course, the job is that the new Secretary of Energy meant none of these. The actual meaning is in the subject line-DOE Labs called to action. 


\section{Examples of different names for the same concept}

"In addition, parts of the pit walls consisted of highly broken rock that was at least partially caused by pit excavation, and measurements were not made if such secondary fractures were suspected. Consequently, some zones of highly fractured tuff were probably not recognized, and the measurements of fracture density may be somewhat underestimated."

The italicized terms state the same concept with different terminology. The italicized terms are describing fracturing, but the wording is different each time.

It would be advisable to rewrite this paragraph using more consistent terminology, For example,

"In addition, parts of the pit walls consisted of secondary fractures. (These fractures consist of highly broken rock caused at least in part by pit excavation.) If secondary fractures were suspected, no measurements were made. Therefore, some secondary fractures in tuff probably were not recognized, and their density may have been underestimated."

\section{Example of using one word for two different meanings}

"It is amazing that the current membrane/electrode assembly with a total thickness of about 200 microns can generate more than half an ampere of current."

\section{Suggestion}

To avoid confusion, we suggest using a different word for the less technical meaning. In this case you might say

"It is amazing that the present membrane/electrode assembly with a total thickness of about 200 microns can generate more than half an ampere of current."

\section{Example}

"The potential impact of lower-emission-gasoline vehicles is offset by the growth of fuel cell potential as an alternative transportation option. However, potential problems may arise from competition for markets."

\section{Suggestion}

In the first and third usages, the word "possible" could be substituted because this is the more general usage. The meaning of the second "potential" is in the sense of electrical power. A rewrite might be

"The possible impact of lower-emission-gasoline vehicles is offset by the growth of fuel cell potential as an alternative transportation option. However, possible problems may arise from competition for markets."

\section{Example}

"A solution of liquid phosphoric acid soaked in a matrix may provide a solution for electrochemical reactions that produce toxic waste products." 


\section{Suggestion}

"A solution of liquid phosphoric acid soaked in a matrix may provide an alternative for of electrochemical reactions that produce toxic waste products."

\section{Example}

"A bipolar plate produces a positive current of $60 \mathrm{~A}$, thus providing a positive result by carrying hydrogen gas on one side and air on the other."

\section{Suggestion}

"A bipolar plate produces a positive current of $60 \mathrm{~A}$, thus providing the desired result by carrying hydrogen gas on one side and air on the other." 



\section{Section 3. Jargon}

It is best to avoid using technical jargon. If using jargon is important to the writer, then define the jargon in the text or in a glossary.

\section{Definition}

Jargon is the specialized or technical language of a trade, profession, or group. Jargon can also be defined as speech or writing having unusual or pretentious vocabulary, convoluted phrasing, and vague meaning. ${ }^{2}$

\section{Example of Jargon}

"Science writers are nearing a breakthrough, perhaps a major breakthrough, in their ageold quest to unlock the secrets, even the ultimate secrets of cliché-free prose, researchers reported yesterday."

\section{Suggested Rewrite}

"Researchers reported yesterday that science writers are nearing a solution, perhaps a major solution, to solving problems of writing clearly."

\section{Example}

"Using cutting-edge, state-of-the-art, high-tech and other dash-laden methodologies, the science journalists sifted obscure clues to reach their tentative conclusions. 'This is statistically significant.' 'It is an important step forward.' 'This is science in action."'

\section{Suggested Rewrite}

"Using the latest methodologies, science journalists searched for meaning in such expressions as 'This (finding) is statistically significant.' 'It is an important step in this research.' This demonstrates progress in science."”

\section{Example}

Science writers covered all the usual bases. Cliches are a window into the past, even if they are redshifted like the whistle on a passing train that changes pitch when it goes by, an analogy that itself is a window into the past.

\section{Suggested Rewrite}

"Science writers included all the important topics. Cliches are often obsolete."

\section{Example}

"And while the latest results do not offer a cure, they point the way to better understanding of the underlying basic cellular causes to the ancient affliction. We may never know all the answers but this is an important piece of the puzzle."

\section{Suggested rewrite}

"And although the latest results do not provide a solution, they provide a better understanding of the cellular causes of this historical disease. We may never know a complete solution, but this information is important in understanding this illness."

\section{Example}

"The Americas are poised on the threshold of a new era in which knowledge, broadly construed, will become a major organizing principle for sustainable human development. The path to a prosperous, sustainable, and equitable society is long, winding, and 
difficult, but a start can now be made with a knowledge-based and human-centered strategy. This strategy empowers individuals to renew rather than degrade the physical and biological environment, and to enrich rather than impoverish the social and cultural environment. Entry into this knowledge society will require new patterns of collaboration among the scholarly disciplines. New modes of partnership must also be established among all levels of government, academia, business and industry, and local community organizations."

\section{Suggested Rewrite}

"The Americas are beginning a new era in which knowledge will be the basis of human development. This knowledge protects the environment and enriches society and culture. In order to base human development on knowledge, researchers in different fields of study must collaborate. In addition, government, academia, business, industry, and local community organizations must establish partnerships at all levels."

\section{Exercises}

1. Analysis provides a more cost-effective method of training development by eliminating guesswork or "sho gunning" the audience with unnecessary training.

2. People, programs, scientific goals, and objectives are constantly changing when working on the "cutting edge" of technology.

3. Managers have found many "spin-off" benefits that have provided additional cost savings.

4. All persons state their ideas in a "round robin." (In this case, the "round robin" means that each person takes a turn giving suggestions from a prepared list. The process continues until each member of the team has had an opportunity to give all his/her suggestions.)

5. Periodic training of a task keeps skills and knowledge sharply honed.

\section{Suggested Rewrites}

1. Analysis provides a more cost-effective method of training development by eliminating estimates so that the audience will not receive unnecessary training.

2. People, programs, scientific goals, and objectives are constantly changing when working on the latest technology.

3. Managers have found many byproducts that have provided additional cost savings.

4. All persons state their ideas in turn from a prepared list.

5. Periodic training of a task keeps skills and knowledge sharp. 


\section{Section 4. Acronyms, Initialisms, and Abbreviations}

\section{Definitions}

An acronym is a word formed from the initial letters of a name, such as WAC for Women's Army Corps. An acronym is also defined as a word formed by combining initial letters or parts of a series of words, such as radar for radio detecting and ranging. An acronym is pronounced as one word.

An initialism is an abbreviation consisting of the first letter or letters of words in a phrase, for example, IRS for Internal Revenue Service, or a combination of words and syllables such as ESP for extrasensory perception. An initialism is pronounced by spelling out the letters one by one, rather than pronouncing them as a solid word.

An abbreviation is a shortened form of a word or phrase used to represent the complete word or phrase, such as Mass. for Massachusetts or USMC for United States Marine Corps. ${ }^{3}$

\section{Background}

Scientific and technical writers in the United States frequently use acronyms, initialisms, and abbreviations to shorten text and because they are sometimes more familiar with the acronym than the actual term. However, these shortcuts will not always enhance communication, especially if the reader is a nonnative English speaker or is someone not in the same field and specialty as the writer. In addition, many acronyms, initialisms, and abbreviations are common locally, but are not used throughout the United States as a whole or in other countries. Therefore, even native English speakers may be puzzled by unfamiliar acronyms.

Although it is not always possible to eliminate them, readers will understand more clearly if acronyms, initialisms, and abbreviations are used as little as possible.

\section{Examples of acronyms}

NASA (National Aeronautics and Space Administration)

AIDS (acquired immune deficiency syndrome)

COBOL (common business-oriented language)

BASIC (beginners' all-purpose symbolic instruction code)

RAM (random access memory)

ROM (read-only memory)

ASCII (American National Standard Code for Information Interchange)

MIRV (multiple independently targetable re-entry vehicles)

\section{Examples of initialisms}

DNA (deoxyribonucleic acid)

ABM (antiballistic missile)

DOE (Department of Energy) 
NTS (Nevada Test Site)

CRT (cathode ray tube)

CPU (central processing unit)

LED (light-emitting diode)

NMR (nuclear magnetic resonance)

Btu (British thermal unit)

\section{Familiarity}

Many acronyms and initialisms are so easily recognized that people have become more familiar with the acronym than the original spelled-out version.

For example, many people are surprised when they learn that "words" such as radar, laser, and scuba are actually acronyms (from radio detecting and ranging, light amplification by stimulated emission of radiation, and self-contained underwater breathing apparatus, respectively). Similarly, initialisms such as GNP (gross national product), TV (television), and IRS (Internal Revenue Service) are generally more widely employed than the phrases for which they stand - to the point that people thoroughly familiar with their meanings may have to think a moment to remember the words for which they stand.

\section{Necessity}

Occasionally, writers may need to create acronyms or initialisms for new ideas or entities. For example, in a technical paper written to introduce a new computer code, the name of the code (which will generally be either an acronym or an initialism) will be unfamiliar to most if not all readers.

\section{Guidelines for general usage and writing for translation}

Writers addressing nonnative-English-speaking audiences should follow the same rules for the use of acronyms and initialisms that apply to good scientific-technical writing in general. But in addition, they should be aware that acronyms and initialisms can be one of the most difficult elements for their audiences to grasp. Moreover, when a document is translated into another language, an acronym or initialism may even have another meaning in the reader's native language. The following rules should guide the use of acronyms and initialisms in papers written in International English.

1. Be sure that the acronyms or initialisms you use are indeed commonly understood in your field of study. Internationally well-known acronyms such as radar may be used without hesitation. If in doubt, define the acronym the first time you use it (write out the entire phrase followed by the acronym in parentheses).

2. Establish a new acronym or initialism only if (1) the phrase is long and cumbersome and is used so frequently that writing it out in full each time becomes awkward, or (2) if you intend the acronym or initialism to become the accepted name for a new idea or entity, such as the name of a newly established organization. Define the acronym or initialism the first time you use it. 
3. Beware of repeating a word that is already included in the acronym or initialism (for example, the "ICC Committee"(the International Communication Committee Committee.)

4. If you use an acronym or initialism in an abstract, define it there and then define it again the first time you use it in the text.

5. If your paper is long and you must use several acronyms and initialisms, provide a glossary.

\section{Abbreviations}

An abbreviation is a shortened form of a word. It may consist of the first letter, such as $s$ for seconds; the first few letters, such as min for minutes; or two or three nonsequential letters that recall the sound of the word, as in mtg. for meeting. It may have an initial capital letter, but the rest are usually lower case. It often is followed by a period (except in some technical usage). These are examples:

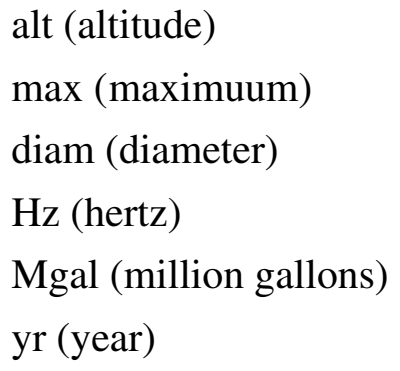

The abbreviations most commonly found in technical documents are those for units of measurement and chemical elements - most of which will be familiar to nonnativeEnglish-speaking technical experts. For this reason, we recommend that when using abbreviations in documents written in international English, the writer should follow the same rules as for documents intended for native-English-speaking audiences.

1. Abbreviate units of measurement when they are preceded by a numeral: for example, "a 6-ft-long pipe."

2. Use the International System of Units for technical abbreviations (see Section 16).

3. Use the appropriate symbols for chemical elements when they are part of a formula or alloy composition; write out the names of elements when they are employed generically in text.

\section{$\mathrm{C}_{2} \mathrm{H}_{5} \mathrm{OH}+\mathrm{CH}_{3} \mathrm{COOH} \rightarrow \mathrm{CH}_{3} \mathrm{COOC}_{2} \mathrm{H}_{5}+\mathrm{H}_{2} \mathrm{O}$}

but spell out the chemical when you are writing in the text of the document.

"Ethyl alcohol combined with acetic acid yields ethyl acetate and water." 


\section{Guideline}

In summary, acronyms, initialisms, and abbreviations should be used in documents intended for nonnative-English-speaking audiences only when there is no doubt that they will be understood. 


\section{Section 5. Inventing Your Own Language}

In an effort to sound more professional, we sometimes use expressions that do not exactly express the meaning we wish to convey. If we invent words, foreign readers and translators will have even more difficulty understanding these expressions.

\section{Examples of Invented Words}

\section{Original}

"The frequency of such an accident with a subsequent fire and lack of extinguishment by personnel is extremely low."

\section{Suggested rewrite}

"The frequency of such an accident causing a fire and personnel not extinguishing it is extremely low."

\section{Examples of Inaccurate Word choice}

\section{Original}

"Action Item: Develop organizational chart for all WXZ operations and dessimate this chart to all personnel."

\section{Rewrite}

"Action Item: Develop an organizational chart for all $\mathrm{WXZ}$ operations and disseminate this chart to all personnel."

\section{Examples of the right word in the wrong place}

\section{Original}

"The unsanitary water is compounded by reports of mass fish asphyxiation fouling the shoreline."

\section{Rewrite}

"In addition to the unsanitary water, the pollution problem of the area is compounded by the vast numbers of asphyxiated fish that foul the shoreline."

\section{Exercises}

1. Subject matter experts must be instructionally qualified (e.g., teaching).

2. Employees who are incomplete or expired on their training requirements are denied access to certain areas.

3. Evaluation reports are generated and submitted to the main office and to other organizations with a vested interest.

4. Adjustments must be appropriate when new or revised information is received through inspection reports, DOE surveys, or job performance anomalies. 
5. The process of job or task analysis is initially resource intensive.

6. The nontraining benefits are job leveling, career pathing, and self-assessment.

7. The process by which a training plan is populated and assignments are reviewed is called maintenance.

8. Information-gathering methods may be used, such as surveys or direct observation, either alone or in conduction with the tabletop method.

9. The same taxonomic number is given to the duty area to facilitate tracking. (Taxonomic means the biological classification of animals.)

10. The division has adopted ANSI 1982 as its prime dimensioning and tolerancing standard manual.

11. At this seminar you will learn about architecting a security solution for your entire organization.

12. The system has been militarized and ruggedized for airborne installation and use.

13. In contrast, the sources consist of very simple, well-known manufactured items that are robustly containerized (e.g., doubly sealed).

14. LANL-wide employee focus teams facilitated by S-Division have developed an integrated set of three security LIRs to cascade from an overarching ISSM LPR.

\section{Suggested Rewrites}

1. Subject matter experts must be qualified to teach.

2. Employees who have not completed training or whose required training has expired are denied access to certain areas.

3. Evaluation reports are generated and submitted to the main office and to other organizations with a need to know.

4. Adjustments must be appropriate when new or revised information is received through inspection reports, DOE surveys, or abnormal job performance reports.

5. The process of job or task analysis initially requires many resources.

6. The nontraining benefits are job leveling, choice a career path, and self-assessment.

7. The process by which a training plan is postulated and assignments are reviewed is called maintenance.

8. Information-gathering methods may be used, such as surveys or direct observation, either alone or in conjunction with the tabletop method.

9. The same categorical number is given to the duty area to facilitate tracking. 
10. The division has adopted ANSI 1982 as its prime model for a standard manual that describes required dimensions and material tolerances.

11. At this seminar you will learn about designing a security solution for your entire organization.

12. The system has been militarized and made sufficiently rugged for airborne installation and use.

13. In contrast, the sources consist of very simple, well-known manufactured items that are placed in strong containers (e.g., doubly sealed).

14. LANL-wide employee focus teams facilitated by S-Division have developed an integrated set of three security LIRs derived from an ISSM LIR. 



\section{Section 6. Wordiness}

Wordiness obscures the message and annoys the reader. Sometimes wordiness obscures meaning, thus making the written words much harder to understand for foreign readers and readers with English as a second language.

\section{Tips for rewriting and simplifying}

Some hints for simplifying your writing are given in the ACS Style Guide ${ }^{3}$ as follows.

Omit these phrases. (Just cross them out! They add nothing to the meaning of your sentence.)

As already stated

It has been found that

It has long been known that

It is interesting to note that

It is worth mentioning at this point that

It may be said that

\section{Samples of wordiness and suggested rewrites}

Instead of "It is a procedure that is often used," try "This procedure is often used."

Instead of "There are seven steps that must be completed," try "Seven steps must be completed."

Instead of "These results are preliminary in nature," try "These results are preliminary."

Try using fewer words, such as

\begin{tabular}{|l|l|}
\hline Instead of & Use \\
\hline A number of & many, several \\
\hline A small number of & a few \\
\hline Are in agreement & agree \\
\hline Are found to be & are \\
\hline At the present time & now \\
\hline
\end{tabular}

Example

"It is a procedure that is often used."

\section{Rewrite}

"This procedure is often used."

\section{Example}

"There are seven steps that must be completed." 


\section{Rewrite}

"Seven steps must be completed."

\section{Example}

"These results are preliminary in nature."

\section{Rewrite}

"These results are preliminary."

In some cases, a group of words may be replaced with just one.

A number of $=$ many or several

A small number of $=\mathrm{a}$ few

Are in agreement $=$ agree

Are found to be $=$ are

Are known to be $=$ are

At present $=$ now

At the present time $=$ now

Based on the fact that $=$ because

By means of $=$ by

Despite the fact that $=$ although

Due to the fact that $=$ because

During that time $=$ while

In the article "How do They Do It? Revisions," in the Editorial Eye gave an example of a rewrite of a selection with fewer words.

"Perceptions are constructs of sensory experiences, which are the only means by which all human beings know the world around them. Once those construct perceptions are stored in memory, they are available for recall as reference standards against which to compare new experiences. On these reference perceptions we build our fears and hopes' our criteria to accept or reject."

\section{Rewrite}

"Humans build perceptions on sensory experiences and then use these perceptions as reference standards in evaluating new situations."

\section{Elaine Campbell's “active” verbs and phrases}

Elaine Campbell ${ }^{5}$ suggests another way to increase your word count needlessly. She calls it nominalization and defines it as changing verbs into noun phrases, making a single word (the verb) grow into multiple words. Therefore, another tactic for reducing words is to change noun phrases into action verbs.

\section{Example}

"He called for the cancellation of the meeting."

\section{Rewrite}

"He cancelled the meeting".

\section{Example}

"The discussion concerned the current research project." 


\section{Rewrite}

"They discussed the current research project."

\section{Example}

"He called for the cancellation of the meeting."

\section{Rewrite}

"He cancelled the meeting."

\section{Example}

"Thousands of Lab employees will be in attendance at the security sessions."

\section{Rewrite}

"Thousands of Lab employees will attend the security sessions."

\section{Example}

1. Serve as a gateway to the broad scientific world through collaborations with government labs; universities; and industry.

\section{Rewrite}

1. Collaborate with government labs, universities, and industry.

The book Style: Ten Lessons in Clarity and Grace 6 reminds us that not all nominalizations are bad, only the useless ones. Williams divides these into five categories.

1. When the nominalization follows an empty verb, change the nominalization to a verb.

\section{Example}

"The researchers conducted an investigation into the causes of the phenomena."

Rewrite

"The researchers investigated the cause of the phenomena."

2. When the nominalization follows a there is or there are, change the nominalization to a verb and find a subject.

\section{Example}

"There is a need for further research into this problem."

\section{Rewrite}

"The researchers at the Laboratory must study this problem further."

3. When the nominalization is the subject of an empty verb, change the nominalization to a verb and find a new subject.

\section{Example}

"The discussion concerned the current research project."

\section{Rewrite}

"They discussed the current research project." 
4. When you find two nominalizations in a row, make at least the first into a verb. Then either leave the second as it is or turn it into a verb in a clause beginning with how or why.

\section{Example}

"There was a first review of the research involved in this scientific discovery."

\section{Rewrite}

"First, we reviewed the research involved in this scientific discovery."

or

"First, we reviewed how this scientific discovery was researched."

5. When a nominalization in a subject is linked to another in the predicate (the rest of the sentence), we have to revise more extensively.

1. Change the abstractions to verbs.

2. Find subjects for those verbs.

3. Link the new clauses with a word that expresses their logical connection.

\section{Example}

"New research into methods for the manufacture of new weapons will have the result of a great increase in the funding for the Laboratory."

\section{Rewrite}

"New weapons research will provide increased funding for the Laboratory." 


\section{Section 7. Overmodified nouns}

\section{Why We Have Overmodified Nouns}

A frequent problem in technical writing is using "stacked" adjectives. Stacked adjectives are strings of adjectives that all modify the same word. Too many adjectives can create sentences so complex that they stop the reader from continuing and thus lose the reader's train of thought.

In Spanish, the endings of adjectives give important clues as to the word they are modifying. In the German language, where words are placed in a sentence indicates what the adjective modifies. But in English, we have no word endings, and adjectives are placed as close to the noun as possible.

\section{Example}

As an example, let's look at a long string of adjectives.

"XYZ requires high quality long term storage secondary tritium containment vessels that fit within a specially designed calorimeter."

\section{Suggested rewrite}

"For long-term storage in a specially designed calorimeter, XYZ requires secondary tritium containment vessels that are high quality."

Sometimes the stacked adjectives can be rearranged, such as in this example.

"Caliber-RT is the prototype functional test case design tool."

\section{Suggested rewrite}

"The test case "Caliber-RT" is the prototype for the functional design tool."

Sometimes stacked adjectives can be clarified with punctuation.

\section{Example}

"The technological social political regulatory and economic external environment has always been a powerful influence on research."

\section{Rewrite}

"The external environment (technological, social, political, and regulatory) has always been a powerful influence on research."

\section{The rules for comma usage are}

Commas can sometimes assist in managing many adjectives.

When two consecutive adjectives modify the same noun, separate the adjectives with a comma.

\section{Example}

"Participants gained a clear understanding of the practical, logical steps." 
When two adjectives precede a noun, the first adjective may modify the combined idea of the second adjective plus the noun. In such cases, do not separate the adjectives by a comma.

\section{Example}

"Huge cost overruns are encountered daily."

When more than two adjectives precede a noun, insert a comma only between those adjectives where the word "and" could have been used.

\section{Example}

"It also discusses roles, and deliverables, and the resources required for effective implementation."

\section{Exercises}

1. The ultramafic rocks consist of variably serpentinized dunite harzburgite and minor lherzolite.

2. Quantitative analysis of mineral phases was performed using a modification of the external standard matrix flushing method of Jones.

3. These include the Marriotsville schist near Baltimore containing substantial tremolite anthophyllite talk and two harzburgites from California with significant but variable orthopyroxene contents.

\section{Suggested Rewrites}

1. The ultramafic rocks consist of variably serpentinized dunite, harzburgite, and minor lherzolite.

2. Quantitative analysis of mineral phases was performed using a modification of the external standard, matrix-flushing method of Jones.

3. These include the Marriotsville schist near Baltimore, containing substantial tremolite anthophyllite talk, and two harzburgites from California (with significant but variable orthopyroxene contents). 


\section{Section 8. Apostrophes and Possessives}

Sometimes possessive nouns obscure the meaning. Avoiding the use of apostrophes can sometimes clarify the meaning of the sentence.

The following suggestions from Frederick $\mathrm{Crews}^{7}$ can help the writer avoid confusing possessives.

1. When an $-s$ possessive sounds awkward, consider shifting to a prepositional form. Especially when there is more than one modifying term, the writer can avoid the "bunched" effect by using "of," "from," or "at."

Example

"The station's common system noise source is coincident with spikes in the relative humidity data."

\section{Suggested rewrite}

"The noise source from the common system of the station is coincident with spikes in the relative humidity data."

2. Avoid separation of the $-\mathrm{s}$ form from the word it belongs with.

Example

"The first phase of the Los Alamos' Dual-Axis Radiographic Hydrotest (DARHT)

Facility was completed on schedule."

\section{Suggested rewrite}

"The first phase of the Dual-Axis Radiographic Hydrotest (DAHRT) Facility at Los Alamos was completed on schedule."

\section{Example}

"The Laboratory's plutonium pit manufacturing facility had not been constructed yet."

\section{Suggested rewrite}

"The facility for manufacturing plutonium pits at the Laboratory had not been constructed yet."

\section{Nouns for inanimate (nonliving) things often make awkward possessives.}

\section{Example}

"Over the next five years, the nation's political, regulatory, and social environment will impose new regulatory requirements upon the Laboratory."

\section{Suggested rewrite}

"Over the next five years, the political, regulatory, and social environment of the nation will impose new regulatory requirements upon the Laboratory."

\section{Exercise}

1. As a statistician, she also designs tools for SATC's reliability research work.

2. Described below is an overview of the Software Engineering Institute's Capability Maturity Model for software. 
3. Other indications of success are the electronic journal Web page's every-increasing usage.

\section{Suggested rewrites}

1. As a statistician, she also designs tools for reliability research work at SATC.

2. Described below is an overview of the Capability Maturity Model software for the Software Engineering Institute.

3. Other indications of success are the ever-increasing usage of the electronic journal Web pages. 


\section{Section 9. Articles}

In grammar, an article is a limiting adjective serving to designate or point out a noun. ${ }^{8}$ An article may be used with or without other adjectives modifying the same noun: "an ability to synthesize," "a computer program, or "the specific atoms."

In English, the indefinite articles are "a" and "an," and the definite article is "the."

"An" is used when the sound of the word following it is a vowel sound: "an RNA protein," "a DNA molecule," and "an additional neutron."

All English nouns can be classified as either common nouns (a boy, a country) or proper nouns (Bill Roberts, Panama). Common nouns may be further categorized as either countable (a suit, a glass) or noncountable (water, sugar).

Countable nouns, such as beetles, books, sounds, concepts, minutes, have both singular and plural forms. In the singular, they must be preceded by a definite or an indefinite article.

The usage of articles ("a," "the," "an") is considered the number-one teaching problem for teachers of English as a second language, as their use is not easily "translated" from one language to another.

Examples

A definite article — "The rocket was launched last year."

An indefinite article— “A rocket was launched last year."

Never omit the article (example: "Rocket was launched.") even though it saves time and space.

In the plural, nouns may occur either with or without an article.

\section{Example}

"Tests are under way to address the ignition of flammable gas in the riser."

or

"The tests will show that the rotational motion of a drill string would not cause ignition in a bounding hydrogen-oxygen mixture."

Noncountable nouns, such as steam, music, justice, advice, have no plural. They are used in the singular as follows:

Without an article — "Information is important."

With a definite article - "The information is important."

(Never with an indefinite article — "An information is important."

As the above examples illustrate, meaning can change completely depending on (a) whether an article is present and (b) whether the article is definite or indefinite.

"Information is important" says something totally different from "The information is important." The former states that all information is important in all cases; the latter states that a particular piece of information is important in a particular case. Similarly, "A rocket was launched" refers to some unknown or unspecified rocket, but "The rocket was 
launched" refers to a particular rocket that we had known about previously. Omission of, or carelessness in choice of, an article can therefore convey an incorrect meaning to a foreign reader.

Some nouns have both a countable and a noncountable form, and generally the two have quite different meanings. In the next example, "activity" is noncountable and therefore exists only in singular form and cannot take an indefinite article:

"Most of the seismic activity was recorded in subvolume 4."

But in the following example, "activities" is a countable noun that is plural and can take either the definite or the indefinite article:

"Most of the activities (or Most activities) planned for the conference were related to the theme of volcanoes."

Foreign readers and speakers of English frequently are unsure whether an article should precede a noun. Part of the confusion lies in the fact that what is considered noncountable varies from language to language. Furniture, for example, is a noncountable noun in English, but in Spanish it is not ("un mueble" is a valid construction). Bread is a noncountable noun in English, but not in Spanish ("un pan").

In this example,

"Although knowledge of the hydrogeology of the basin is very limited, it would be difficult to sufficiently drain the bog to allow for peat harvesting,"

knowledge and peat harvesting are noncountable nouns and require no articles.

However, if a noncountable noun is particularized by the addition of a restrictive modifier, the definite article is required.

"Although the knowledge that we have gained of the hydrogeology of the basin is very limited, it would be difficult to sufficiently drain the bog to allow for the peat harvesting that has been recommended by experts."

Similarly, in the following example, production is one of those nouns that has both a countable and a noncountable form:

"A total of two sod-peat basins will be required to provide for $a$ continuous production."

In this context, production is noncountable, and therefore the article "a" should not be used. In such examples, meaning is not seriously distorted by the incorrect usage of articles, but compare sentences such as

"Although the basins present many geological anomalies, the survey may provide sufficient data for evaluating their potential."

"Although the basins present many geological anomalies, a survey may provide sufficient data for evaluating their potential."

In the first case, the reader understands that a survey has been done. In the second, a survey is being proposed. In other words, the definite article signals a particular item that has been singled out from among other possible items. The indefinite article signals an 
unspecified item among other possible items.

This next example further illustrates the need for care in the use of articles.

"This structure was a concrete waste tank that received discharges from the dark room and processing room in Building 6."

How many rooms are involved? Is there one room used both as a darkroom and as a processing room, or are there two? Actually, there are two, so articles are appropriate to make this clear.

"This structure was a concrete waste tank that received discharges from the dark room and the processing room in Building 6."

Similarly, from the following:

"Fractures range in width from a few millimeters to several centimeters. Larger fractures may be filled with rubble."

It could be understood that fractures larger than the range given are filled with rubble.

But, by adding the definite article,

"Fractures range in width from a few millimeters to several centimeters. The larger fractures may be filled with rubble."

The article makes it clear that "larger" refers only to those fractures within the range.

\section{Exercises}

1. Vines and the Yolillo palm cover the peat bog area.

2. When operating procedures based on this safety analysis (SA) are complete, test review group must review and approve them to ensure the consistency between SA and procedures.

3. Because some of design/system/procedure descriptions were written on the basis of verbal information from cognizant engineers, we require WHC engineers and technicians to sign affidavit given at end of this section.

4. Use of current bit ignited the $\mathrm{H}_{2} \mathrm{O}_{2}$ when assorted rocks were drilled.

5. Drill bit is being redesigned to replace stainless-steel pins and base with a soft teeth.

6. Total number of tests conducted in the hydrogen-oxygen mixture will be 12 .

7. These systems are known to be sensitive to orientation, flow rate, and pressure.

8. Sample is placed in sealed container to be $\mathrm{x}$-rayed.

\section{Answers}

1. Vines and Yolillo palm cover the peat bog area.

2. When operating procedures based on this safety analysis (SA) are complete, the test review group must review and approve them to ensure the consistency between the SA and procedures. 
3. Because some of design/system/procedure descriptions were written on the basis of verbal information from cognizant engineers, we require that WHC engineers and technicians sign the affidavit given at end of this section.

4. The use of the current bit ignited the $\mathrm{H}_{2} \mathrm{O}_{2}$ when assorted rocks were drilled.

5. The drill bit is being redesigned to replace stainless-steel pins and the base with soft teeth.

6. The total number of tests conducted in the hydrogen-oxygen mixture will be 12 .

7. These systems are known to be sensitive to the orientation, flow rate, and pressure.

8. The sample is placed in $a$ sealed container to be x-rayed. 


\section{Section 10. Active Voice.}

\section{Why Use the Active Voice?}

The active voice is the most direct way of expressing an idea. However, it may not always be possible to use it, and in technical papers, the actor may not be the important issue at the moment. Patricia T. O'Conner expresses this idea in a humorous way, "Always use an active verb (Bonnie drove the getaway car) and avoid a passive one (The getaway car was driven by Bonnie). It's true that a passive verb makes for a more wimpy, roundabout way of saying something. The more straightforward way is to put in the one performing the action (Bonnie) ahead of the one being acted upon (the getaway car), with the verb in between: subject. . .verb . . . object. But the direct way isn't always the best way. The passive might be more appropriate in cases like these,

- When there's a punch line. You might want to place the one performing the action at the end of the sentence for emphasis or surprise: The gold medal in the 500 meter one-man bobsled competition has been won by a six-year-old child!

- When nobody cares whodunit. Sometimes the one performing the action isn't even mentioned:" Hermione has been arrested. Witherspoon is being treated for a gunshot wound. We don't need to know who put the cuffs on Hermione or who's stitching up Witherspoon."

- When you want to use fewer words and therefore communicate more clearly.

\section{Example}

"Presentations will be made by Los Alamos National Laboratory, state and other officials who were on the scene and worked to bring the fire under control." (26 words)

\section{Rewrite}

"Los Alamos National Laboratory, state, and other officials who worked to bring the fire under control will give presentations." (19 words)

\section{Example}

"This objective could also be geared to increasing your knowledge of (the) client's work if you're on assignment."

\section{Rewrite}

"You could also gear this objective to increasing your knowledge of the client's work if you're on assignment."

\section{Example}

"Editors would have to be given some AD time for such work."

\section{Rewrite}

"We would have to give editors some AD time for such work."

\section{Example}

"Its usefulness is restricted to experiments where the compressive stress is large." 


\section{Rewrite}

"The experiments are useful only when the compressive stress is large."

\section{Example}

"Errors incurred by this approximation are easily quantified."

\section{Rewrite}

"We can easily quantify errors resulting from this approximation."

\section{Example}

"A check of the vacuum integrity of the LH transfer line's vacuum jacket should be accomplished before system startup." (19 words)

\section{Rewrite}

"Check the vacuum integrity of the LH transfer line's vacuum jacket before system startup." (14 words)

\section{Exercises}

1. Before the installation of the new moderator, Flight Path 10 will have to be dismantled to access the area where the moderator will be installed.

2. The moderator must then be installed, aligned, and secured in its vacuum space.

3. Overpressure of the system is protected by the use of multiple overpressure relief devices.

4. This valve is controlled by relay logic, using inputs from the combustible gas detector.

5. Any system fault that causes a release of hydrogen gas into the service area will be detected by the detectors.

\section{Answers}

1. Before the installation of the new moderator, dismantle Flight Path 10 to access the area where you are to install the moderator.

2. Then install, align, and secure the moderator in its vacuum space.

3. Protect the system overpressure by using multiple overpressure relief devices.

4. Control this valve by relay logic by using inputs from the combustible gas detector.

5. The detectors will find any system fault that causes a release of hydrogen gas into the service area. 


\section{Section 11. Correct Verb Tenses}

\section{Sequence of tenses}

The correct use of verb tenses in English writing, technical or otherwise, may be the least well understood of all grammatical issues. English follows the "sequence of tenses": the main verb in a sentence governs the tense of the dependent verbs. Thus, a verb may occur in a past tense without actually conveying the sense of past action, as in "The report stated that the researchers were all natives of England." (The researchers still are natives of England, but the dependent verb is expressed in the past for the sake of harmony with the main verb, "stated.")

In accordance with the sequence of tenses, a past main verb often requires a past form in a direct object clause. A present main verb, however, may be followed by any of a variety of dependent verb tenses, depending on the intended meaning.

\begin{tabular}{|l|l|}
\hline $\begin{array}{c}\text { Main Verb in Present Tense (sequence } \\
\text { of tenses not followed) }\end{array}$ & \multicolumn{1}{|c|}{$\begin{array}{c}\text { Main Verb in Past Tense (sequence of } \\
\text { tenses followed) }\end{array}$} \\
\hline The annual report states (that) & The annual report stated (that) \\
\hline $\begin{array}{l}\text { field testing always improves groundwater } \\
\text { remediation. }\end{array}$ & $\begin{array}{l}\text { field testing always improved } \\
\text { groundwater remediation. }\end{array}$ \\
\hline $\begin{array}{l}\text { field testing is improving groundwater } \\
\text { remediation. }\end{array}$ & $\begin{array}{l}\text { field testing was improving groundwater } \\
\text { remediation many years ago. }\end{array}$ \\
\hline $\begin{array}{l}\text { field testing has improved groundwater } \\
\text { remediation. }\end{array}$ & $\begin{array}{l}\text { field testing had improved groundwater } \\
\text { remediation. }\end{array}$ \\
\hline $\begin{array}{l}\text { field testing has just improved } \\
\text { groundwater remediation. }\end{array}$ & $\begin{array}{l}\text { field testing had just improved } \\
\text { groundwater remediation. }\end{array}$ \\
\hline $\begin{array}{l}\text { field testing will improve groundwater } \\
\text { remediation. }\end{array}$ & $\begin{array}{l}\text { field testing would improve groundwater } \\
\text { remediation soon. }\end{array}$ \\
\hline $\begin{array}{l}\text { field testing may be improving } \\
\text { groundwater remediation soon. }\end{array}$ & $\begin{array}{l}\text { field testing might be improving } \\
\text { groundwater remediation soon. }\end{array}$ \\
\hline
\end{tabular}

Some exceptions to the examples in the table should be noted.

\section{The present tense is used after a past main verb to express a timeless or} customary action or a general truth. (Note that when such an expression is interjected into a description of past events, it may be helpful to the reader if the interjected material is enclosed in parentheses.)

"When members of John C. Fremont's expedition discovered geothermal manifestations in northern California in 1847, they named the locality 'The Geysers.' In 1957, drilling revealed a steamfield at depth, which became known as 'The Geysers steamfield'.'

\section{Informally, the past tense is often used instead of the past perfect in noun clauses after past main verbs. \\ "The annual report stated that field testing improved groundwater remediation."}

\section{Use the past perfect for actions occurring before those expressed by the simple past.}


Probably the most common error in the use of tenses in modern-day English writing, technical or nontechnical, is the failure to distinguish between the simple past and the past perfect. Although the simple past tense refers to actions completed in the past, the past perfect tense refers to actions completed before "simple past" actions.

In the following example, all the verbs are in the simple past tense:

"After the fittings were welded, several leaked. These were replaced, but some of the new fittings also leaked. A careful check showed that the leaks were in the stainless-toaluminum bond, not in the e-beam weld. This was puzzling, because a significant amount of development work was done to qualify the T-fittings for cryogenic use-including welding several fittings into aluminum blocks and performing torsion and hydrostatic tests. Over 100 tests were done and no leaks were detected."

Analysis of the meaning of the paragraph makes it clear that some of the actions were completed before others. Therefore, the past perfect verb form is required for those actions.

"After the fittings had been welded, several leaked. These were replaced, but some of the new fittings also leaked. A careful check showed that the leaks were in the stainlessto-aluminum bond, not in the e-beam weld. This was puzzling, because a significant amount of development work had been done to qualify the T-fittings for cryogenic use-including welding several fittings into aluminum blocks and performing torsion and hydrostatic tests. Over 100 tests had been done and no leaks had been detected."

Here is another example that illustrates failure to distinguish between the simple past and past perfect tenses.

"That water might be flowing from the experimental trenches to Trench 27 was suggested by Kirby, after detecting a bromide tracer in Sump No. 1 of Trench 27. The tracer was placed in the experimental trenches before trench closure."

Because it is obvious that the placement of the tracer in the experimental trenches would have had to precede its detection in Trench 27 by some reasonable period of time, the last sentence should have read,

"The tracer had been placed in the experimental trenches before trench closure."

For the same reason, this sentence from the same report needs a past perfect in the first phrase.

"There appears to be a slight increase in all values after Trench 27 was covered with plastic in late 1981."

"There appears to have been a slight increase in all values after Trench 27 was covered with plastic in late 1981."

\section{Observe the special use of tenses in the subjunctive mood.}

As classically defined, the subjunctive expresses conditions other than actually existing ones, such as wishes, commands, and "contrary-to-fact" situations. In modern English, use of the subjunctive has been gradually disappearing. But certain constructions - although often found erroneously containing the indicative-still require the subjunctive, as in the following sentence: 
"It is important that the samples are not stored for long periods and are not exposed to freezing temperatures." [correct: "that the samples not be stored. . not be exposed"]

In the following example, the initial phrase describes what is clearly a contrary-to-fact condition:

"If such technology was not in existence, our understanding of hydrologic processes in these arid regions would be far less advanced."

In other words, it is clear from the context that the technology does exist, and therefore the subjunctive is called for.

"If such technology were not in existence ...."

Note that the subjunctive is not used when "if" simply serves to introduce a conditional expression of uncertainty and not one that is contrary to fact.

"No dicarbide phase was found in the specimens. If it was present, it was poorly crystallized or preferentially oriented, making quantitative analyses uncertain."

"Goff and Donnelly point out that if the Na-K-Ca geothermometer is reliable, the results indicate a geothermal reservoir beneath a large area of land northeast of Clear Lake."

Because many other languages have retained the subjunctive to a greater extent than English has, nonnative English speakers are likely to be even more attuned to errors involving the subjunctive than native English speakers are.

\section{Exercises}

1. GRW predicted that the changes in wide-angle curves were the same.

2. Local crustal heat generation is only moderate; if it were high, heat flow will be enhanced.

3. These changes occurred as the surface material is forced into a new shape.

4. As instabilities begin to develop, the material would expand uncontrollably.

5. Once the model passed the required tests, we will conduct a series of real-time analyses using lateral boundary conditions.

6. If this last stimulation were not accompanied by seismic activity, there is no reason to assume that fracturing took place.

7. The original model had the limitation that stress was a single-valued, increasing function of strain.

8. Accordingly, if a shallow temperature anomaly exists beneath area $\mathrm{B}$, it is not hot enough to be detected by this method. (In this case, the author interpreted the sentence as a supposition and therefore used the indicative.)

9. The original model had the limitation that stress is a single-valued, increasing function of strain. 


\section{Answers}

1. GRW predicted that the changes in wide-angle curves would be the same.

2. Local crustal heat generation is only moderate; if it were high, heat flow would be enhanced.

3. These changes occurred as the surface material was forced into a new shape.

4. As instabilities begin to develop, the material will expand uncontrollably.

5. Once the model passed the required tests, we conducted a series of real-time analyses using lateral boundary conditions.

Or

Once the model has passed the required tests, we will conduct a series of real-time analyses using lateral boundary conditions.

6. If this last stimulation were not accompanied by seismic activity, there would be no reason to assume that fracturing took place.

7. The original model had the limitation that stress be a single-valued, increasing function of strain.

8. Accordingly, if a shallow temperature anomaly exists beneath area $\mathrm{B}$, it is not hot enough to be detected by this method. (In this case, the author interpreted the sentence as a supposition and therefore used the indicative.)

9. The original model had the limitation that stress be a single-valued, increasing function of strain. 


\section{Section 12. Sentence and Structure}

\section{Balance longer sentences against shorter ones.}

Unlike systems designed for low-literacy readers, International English welcomes variations in both sentence length and sentence structure. In accordance with general principles of good writing, longer sentences should be balanced against shorter ones. It is not always easy to judge when the length of a sentence is "excessive." Within certain bounds, different writers will have different opinions; beyond those bounds, most will agree. For example, this sentence is clearly excessively long:

"The conductive regime is a thick slab of Franciscan rock that comes to the surface at The Geysers and at Clear Lake but is downfaulted and buried under Clear Lake volcanics in the intervening country and is sufficiently thick and homogeneous that the isotherms of subsurface profiles show smooth, near-horizontal, and level surfaces along the magmatic axis."

For many long sentences, however, the issue of length is not so apparent, each writer will need to exercise personal judgment about the length of a particular sentence. If the writer suspects that a given sentence is too long for ready comprehension by a native English speaker, the same sentence will undoubtedly be too long for a nonnative speaker.

\section{Compound/complex structure plus excessive length hinders comprehension.}

When a sentence is not only long but also compound/complex in structure (contains two or more independent clauses and at least one dependent clause), its chances of being difficult to understand increase. This combination forces the foreign reader to simultaneously deal with multiple ideas, a hierarchy of thoughts, and a large number of words. The following sentence is an example:

"All of the gases produced during the latter half of this operation are inert and, under normal conditions, do not present any hazards, but if the operation is carried out in a small, unventilated area and personnel are not supplied with appropriate protective equipment, the gases could be asphyxiant hazards or could cause irritation of the lungs."

The meaning of such a sentence is not easily grasped in a single reading. One way to increase the readability of this sentence would be to break it into shorter sentences.

"The gases that are produced during the latter half of this operation are inert and, under normal conditions, do not present any hazards. However, if the operation is carried out in a small, unventilated area, the gases could be asphyxiant hazards or cause lung irritation. Personnel should be supplied with appropriate protective equipment."

The following compound/complex sentence, which has three dependent clauses in addition to two independent clauses, illustrates well how, in combination with length, this structure can hinder comprehension:

"The magnitude of the pressure rise at the production well points to the presence of a steep gradient near that well, which represents the largest pressure drop between wells AR-1 and AR-3, and the residual pressure difference between the injection and production wells that is observed following the initial rapid changes indicates that the impedance of the body of the reservoir is moderate." 
At best, such sentences force the reader to go back and mentally analyze each piece - or, at worst, to abandon the effort in frustration. This sentence is also both long and compound/complex.

"The objective of this study, which was carried out on a semiarid hillslope in northern New Mexico, was to obtain field data on the interflow process in a little-studied environment, and on the basis of the data we have developed a conceptual flow model for evaluation of the potential for contaminant transport at similar locations."

Clearly, this sentence becomes far more accessible when rewritten as two more concise sentences:

"This study was carried out on a semiarid hillslope in northern New Mexico, an environment little studied to date. Its objective was to obtain field data on the interflow process, enabling us to develop a conceptual model of contaminant transport in such environments."

\section{Avoid as well the other extreme: short, choppy sentences.}

Be careful, however, when rewriting long and complicated sentences not to break them into too many pieces; the result will often sound simplistic, choppy, and/or repetitive.

"This study was carried out on a semiarid hillslope. The hillslope is located in northern New Mexico. This area represents an environment little studied to date. The objective of the study was to obtain field data on the interflow process. This data should enable us to develop a conceptual model of contaminant transport in semiarid environments."

Some compound/complex sentences may become excessively long through an "overloading" of prepositional phrases.

"Table 3 lists the model results, for the five estimated reservoir volumes, of cooldown times to the model-comparison temperature of $210^{\circ} \mathrm{C}$ and the abandonment temperature of $150^{\circ} \mathrm{C}$, and it presents the results as a function of mean fracture spacing at the anticipated steady flow rate of $8 \mathrm{~kg} / \mathrm{s}$ over the life of the test."

Rearranging the ideas into two shorter (but not overly short) sentences is a good solution:

"Table 3 shows the time periods calculated via the model for the reservoir to cool to the model-comparison temperature of $210^{\circ} \mathrm{C}$ and the abandonment temperature of $150^{\circ} \mathrm{C}$. These time periods were calculated for the five estimated reservoir volumes as a function of mean fracture spacing at an anticipated steady flow rate of $8 \mathrm{~kg} / \mathrm{s}$ over the life of the test."

In summary, sentences may be long if they are clear. Long sentences generally should not be compound/complex in structure. When rewriting sentences whose meaning is obscured by length and/or by compound/complex structure, be careful not to go to the other extreme and write sentences that are too short and choppy.

\section{Exercises}

1. The solution for these nuclide concentrations was simplified in 1962 with the CINDER code. This code resolved the complicated nuclide couplings into linear chains. Each chain represents a unique path from nuclide to nuclide. This results in small independent sets of differential 
equations. The equations describe the rate of change of partial concentrations of nuclides in each chain.

2. Several of the agencies that provide assistance to youngsters who seek higher education decided to change their original policy because of the potential for abuses, and at least two of them recently announced a new set of guidelines, which most people think represent a step backward rather than a step forward.

3. The satellite structure is an excellent example of the simple, cost-effective use of composites for spacecraft structures that feature an all-composite graphite/epoxy frame structure that is the first of its kind with payload platforms constructed of lightweight aluminum honeycomb with graphite/epoxy skins, and EFA developed this innovative and unique satellite structure through a successful teaming arrangement with CompOp, Inc.

\section{Answers}

1. The solution for these nuclide concentrations was simplified in 1962 with the CINDER code, which resolved the complicated nuclide couplings into linear chains. Each chain represents a unique path from nuclide to nuclide and results in small independent sets of differential equations. The equations describe the rate of change of partial concentrations of nuclides in each chain.

2. Several of the agencies that provide assistance to youngsters who seek higher education decided to change their original policy because of potential abuses. At least two of them recently announced a new set of guidelines that most people believe is a step backward rather than a step forward.

3. The satellite structure is an excellent example of the simple, cost-effective use of composites for spacecraft structures that feature an all-composite graphite/epoxy frame structure. This structure is the first of its kind with payload platforms constructed of lightweight aluminum honeycomb with graphite/epoxy skin. EFA developed this innovative and unique satellite structure through a successful teaming arrangement with CompOp, Inc. 



\section{Section 13. Word Order}

Word order is important for clarity. In the following examples the word "only" is used in ten different positions with a different meaning for each. ${ }^{10}$

1. Only I helped my dog carry my husband's slippers yesterday. (Usually the cat helps too, but she was busy with a mouse.)

2. I only helped my dog carry my husband's slippers yesterday. (The dog wanted me to carry them all by myself, but I refused.)

3. I helped only my dog carry my husband's slippers yesterday. (I was too busy to help my neighbor's dog when he carried them.)

4. I helped my only dog carry my husband's slippers yesterday. (I considered getting another dog, but the cat disapproved.)

5. I helped my dog only carry my husband's slippers yesterday. (I didn't help the dog eat them; I usually let the cat do that.)

6. I helped my dog carry only my husband's slippers yesterday. (My dog and I didn't have time to help my neighbor's husband.)

7. I helped my dog carry my only husband's slippers yesterday. (I considered getting another husband, but one is enough.)

8. I helped my dog carry my husband's only slippers yesterday. (My husband had two pairs of slippers, but the cat ate one pair.)

9. I helped my dog carry my husband's slippers only yesterday. (And now the dog wants help again; I wish he'd ask the cat.)

10. I helped my dog carry my husband's slippers yesterday only. (And believe me, once was enough-the slippers tasted terrible.)

Now, for more technical examples,

\section{Example:}

This decision decreased the risk to only that incurred during the continued storage and maintenance of the low-purity materials.

\section{Rewrite:}

This decision decreased the risk to that incurred only during the continued storage and maintenance of the low-purity materials.

\section{Example:}

We also determined previously that these predictions are supported by the measurements.

\section{Rewrite:}

We had also previously determined that these predictions are supported by the measurements. 


\section{Example:}

The returning signal only becomes evident when the echoes are superimposed.

\section{Rewrite:}

The returning signal becomes evident only when the echoes are superimposed.

\section{Exercises}

1. Although all regulations equally apply to the sealed sources as they would to other waste streams, characteristics of the sealed sources ensure fewer constraints in complying with the regulations.

2. These late-time oscillations can be almost eliminated by treating the aluminum as a quasi-elastic material.

\section{Answers}

1. Although all regulations apply equally to the sealed sources as they would to other waste streams, characteristics of the sealed sources ensure fewer constraints in complying with the regulations.

2. These late-time oscillations can almost be eliminated by treating the aluminum as a quasi-elastic material. 


\section{Section 14. Ellipses}

\section{Ellipses Defined}

We are defining ellipses as omitted words that may confuse meaning. Although native speakers may mentally interject the correct word, the foreign reader will have much more difficulty. Note that I have said the native speaker may choose the correct word. In any instance in which the reader may be confused and have to reread the sentence to understand it, you have interrupted his/her train of thought and have prevented comprehension.

\section{Ways to Avoid Ellipses}

1. Include all articles, pronouns, conjunctions, or prepositions necessary for clarity. To make the parallel (sentence) clear, repeat a preposition, an article, the to of the infinitive, or the introductory word of a phrase or clause;

2. Include necessary verbs and auxiliaries;

3. Form complete comparisons; and

4. Be sure to include the word "that" in writing. An example is "I noticed that many benchtop experiments have been done under water-flow conditions."

\section{Examples using "the," "to," and "in" (articles and prepositions)}

"During (the) manufacture of the dual-disk design, careful consideration should be given to lot-to-lot differences in burst disk material properties and (to) maintaining a consistent fabrication process."

"Privacy screens are located in the decontamination rooms as well as (in) many PF-4 laboratories."

"Resistance upset weld parameters were developed for this particular design so as to minimize the side effects on the burst-disk performance and (to) provide high-quality welds."

\section{2. and 3. Examples using a complete comparison and necessary verbs and auxiliaries.}

"Many subsurface contamination and remediation laboratory (e.g., benchtop experiments) have been done under either "pour" or water-flow conditions facilitated by the presence of a gradient in hydraulic pressure and corresponding to the favorite advective conditions mentioned in the preceding. However, relatively few (have been done) under the relatively quiescent conditions of low flow rates and/or low permeabilities that can apply to residual saturation conditions developed gradually over periods of decades after the initial "spills'."

"This solution must be consistent with DOE requirements and the Laboratory mission (must be) capable of withstanding internal and external scrutiny."

"The managers admired him and he (admired) them." 
"In New Mexico there were two such institutions; in Colorado, (there was) one; in Texas, (there were) three."

"These include data from silicon measured at the Los Alamos Bright Source Facility and (at) the Cornell University X-Pinch Facility (where the data have been) studied and (have been) shown to have a strong dependence on electron beam effects."

\section{Examples using "that are"}

"This approach permitted ratio measurements (that are) relatively sensitive and selective to the effect of ultrasonic excitation."

"Buildings (that are) not monitored through the Operations Center (like PF-264 and the TA-55 trailers) have independent fire alarm systems that send a signal directly to the Los Alamos Fire Department."

"The vibrational temperatures obtained for the nitrogen/oxygen mixtures were used to improve the oxygen potential function (that was) used to calculate equation-of-state pressures and temperatures."

\section{Examples using "that"}

"We believe that the most uniform thickness distribution will be achieved with this approach and (that) there is some evidence to support this claim exhibited in Figure 6, where the box is thicker than (that) measured near the corner, despite being modeled with a sharp transition there."

"Appropriate precautions are taken to ensure (that) employees are properly protected."

"Ensure that decontamination solutions appropriate for the hazardous chemicals are available and (that) employees know their location."

"The DOT prompt indicates (that) the link between OS-2 and CRM-2 has been completed and (that) data can be sent and/or retrieved from CRM-2."

"This permit is valid for one year and certifies (that) the individual performing the work has the necessary training and experience."

"In addition, it is the user group leader's and nuclear material custodian's responsibility to ensure (that) their material surveillance procedures are effectively implemented."

"Any access of these exits requires (that) an SPO be present to control movement and perform a hand-held SNM and metal inspection with appropriate detectors."

"We also include in this section so-called "telegraphic writing," which leaves out articles and other important words. This is particularly interruptive when the rest of the selection is written in standard sentence structure."

\section{Example}

"Place vial with water only in position "A" in large water bath. Insert hydrophone and measure voltage. Withdraw hydrophone, replace vial with vial with WSS column. Insert hydrophone into WSS column in this vial using ultrasonics to assist penetration. Measure voltage again. Transfer hydrophone and vial to reference position "B." Spike second 
WSS vial with TCE and place in sampling position "A". Take $200 \mu \mathrm{L}$ water sample immediately, then others $8 \mathrm{~h}$ later and next morning for analysis of TCE levels."

\section{Rewrite}

"Place (the) vial with water only in position "A" in $(a)$ large water bath. Insert (the) hydrophone and measure (the) voltage. Withdraw (the) hydrophone, (and) replace (the) vial with (the) vial (having the) WSS column. Insert (the) hydrophone into (the) WSS column in this vial using ultrasonics to assist penetration. Measure (the) voltage again. Transfer (the) hydrophone and (the) vial to (the) reference position "B." Spike (the) second WSS vial with TCE and place (it) in (the) sampling position "A." Take (a) 200 $\mu \mathrm{L}$ water sample immediately, others $8 \mathrm{~h}$ later, and (the) next morning for (an) analysis of (the) TCE levels."

\section{Example}

"Generated monthly for OS-2, copy is sent over to CRM-1 micrographics for microfilming and stored permanently at CRM-1 Records and Storage Facility."

\section{Rewrite}

"Generated monthly for OS-2, $(a)$ copy is sent over to CRM-1 micrographics for microfilming and (is) stored permanently at CRM-1 Records and Storage Facility."

\section{Example}

"This standard practice is to be used as guide when new program plans are written or existing PPs are revised."

\section{Rewrite}

"This standard practice is to be used as $(a)$ guide when new program plans are written or (when) existing PPs are revised."

\section{Example}

"Station shut down, power up, reprogrammed and restarted at about 00:15 UCC."

\section{Rewrite}

"(The) station (is) shut down, power(ed) up, reprogrammed, and restarted at about 00:15 UCC."

\section{Example}

"Functioning OK, very cold."

\section{Rewrite}

"(The station is) functioning OK, (but it is) very cold."

\section{Example}

"Readings no longer static but high."

\section{Rewrite}

"(The) readings (are) no longer static, but (they are) high."

\section{Example}

"Restarted on 8 Nov at 2113Z."

\section{Rewrite}

"(The station was) restarted on November 8 at 21:31, (Zulu time)." 


\section{Exercises}

1. $\beta, b, d$ and $n$ are viscous drag coefficient, Berger's vector, distance between pinning centers and line density of pinned dislocations.

2. Reader is referred to cited paper for details of model and more precise definition of terms.

3. Notice this "zero stress" behavior only occurs at one position.

4. Entropy changes have been normalized to molar content of magnetic atom.

5. This work is continuation of LAND project.

6. Table 1 defines minimum necessary to model hydraulics of gas pipelines.

7. The voltage sources are connected to current listener.

8. However, it enhances high performance requirement.

9. This problem was eliminated by the use of data table that defined connection with buses.

10. Radiocarbon dates obtained from charcoal in a fissure fill sequence of borehole $\mathrm{XYZ}$ imply a seismic event sometime prior to $8{ }^{14} \mathrm{C} \mathrm{Ka}$ was necessary to open the fissure and initiate sedimentation.

11. Thin sections reveal these clots are commonly cored with plagioclase.

\section{Answers}

1. (The symbols) $\beta, b, d$ and $n$ are the viscous drag coefficient, Berger's vector, the distance between pinning centers, and the line density of pinned dislocations.

2. The reader is referred to the cited paper for details of the model and $a$ more precise definition of terms.

3. Notice that this "zero stress" behavior only occurs at one position.

4. The entropy changes have been normalized to the molar content of the magnetic atom.

5. This work is $a$ continuation of the LAND project.

6. Table 1 defines $a$ minimum necessary to model the hydraulics of gas pipelines.

7. The voltage sources are connected to the current listener.

8. However, it enhances the high performance requirement.

9. This problem was eliminated by the use of $a$ data table that defined the connection with the buses.

10. Radiocarbon dates obtained from charcoal in a fissure fill sequence of borehole $X Y Z$ imply that a seismic event sometime prior to $8{ }^{14} \mathrm{C} \mathrm{Ka}$ was necessary to open the fissure and initiate sedimentation. 
11. Thin sections reveal that these clots are commonly cored with plagioclase. 



\section{Section 15. Nonrestrictive and Introductory Elements}

\section{Definition of a nonrestrictive clause}

A nonrestrictive clause or phrase is one that describes, but does not identify or restrict, the meaning of the noun, phrase, or clause it modifies. In the following sentence, the phrase "which is at an elevation of 2,133 m" is nonrestrictive:

"The site, which is at an elevation of 2,133 m, has a semiarid, temperate mountain climate."

For the phrase to be restrictive, it would have to identify the site, that is, provide information that differentiates that site from other sites. The use of "that" rather than "which" and the omission of the commas make such a phrase restrictive:

"The site that is at an elevation of 2133 m has a semiarid, temperate mountain climate."

In the first example, the site having a semiarid, temperate mountain climate may be only one of many sites at $2,133 \mathrm{~m}$ (the phrase about elevation is not restricted to this one site); but in the second example, we are being told that only one of the sites included in this particular discussion, the one at $2,133 \mathrm{~m}$, has a semiarid, temperate mountain climate. Although "that" should always be used instead of "which" to introduce a restrictive phrase, failure to make this distinction is very common:

"The site which is at an elevation of 2,133 $\mathrm{m}$ has a. ..."

It is now impossible to tell whether the phrase was intended to be restrictive or nonrestrictive. Because "which" is so commonly used for both, the addition of commas to indicate nonrestrictive meaning is imperative.

\section{A comma should also be used to separate introductory elements from the body of the sentence. \\ In the absence of samples of known composition, spikes or surrogates may be added to the sample matrix.}

"On the basis of these new findings, we have revised the model."

In the following example, a nonrestrictive phrase is contained within the introductory element, and both are set off by commas:

"Using RESRAD, an exposure model for assessing radionuclide doses to humans, we have demonstrated that interflow can be an important contaminant transport mechanism in semiarid environments."

The following examples show how confusion and/or ambiguity can result from something as "inconsequential" as omission of a comma:

\section{Example}

"After the spring of 1994 digestion method 3051 was used for sediments and 3015 was used for waters."

\section{Rewrite}

"After the spring of 1994, digestion method 3051 was used for sediments, and 3015 was used for waters." 


\section{Example}

"According to a recent report of the gases generated by human activity $\mathrm{CO}_{2}$ is probably increasing most rapidly in the atmosphere."

\section{Rewrite}

"According to a recent report of the gases generated by human activity, $\mathrm{CO}_{2}$ is probably increasing most rapidly in the atmosphere."

\section{Example}

"Building on his geomorphic work immediately south of Los Alamos Canyon McCalpin (1998) found evidence for a faulting event between roughly 1,500 and 2,500 years ago."

\section{Rewrite}

"Building on his geomorphic work immediately south of Los Alamos Canyon, McCalpin (1998) found evidence for a faulting event between roughly 1,500 and 2,500 years ago."

\section{Exercises}

Place commas in the following sentences as needed to clarify or to resolve ambiguity.

1. Important as they are technological innovations alone will not solve the problem of environmental degradation.

2. Because a stratigraphic section is missing the three major local faults have incomplete paleoseismic histories.

3. The second cross section which is marked with an asterisk goes into equilibrium particle emission.

4. Aside from facility planning a number of other pre-incident plans are available should an emergency occur.

5. If individuals are determined (to be) missing a secondary sweep of the areas they may have been working in will be carried out.

\section{Answers}

1. Important as they are, technological innovations alone will not solve the problem of environmental degradation.

2. Because a stratigraphic section is missing, the three major local faults have incomplete paleoseismic histories.

3. The second cross section, which is marked with an asterisk, goes into equilibrium particle emission.

4. Aside from facility planning, a number of other pre-incident plans are available should an emergency occur.

5. If individuals are determined (to be) missing, a secondary sweep of the areas they may have been working in will be carried out. 


\section{Section 16. Standard International Conventions}

\section{History of SI Units}

The decimal system was conceived in the $16^{\text {th }}$ century when there were many units of weights and measures. ${ }^{11}$ It was not until 1790 that the French National Assembly asked for a system of units suitable for the entire world. Almost 100 years later, in 1870, the General Conference on Weights and Measures (CGPM) was set up by fifteen nations to handle all international matters related to the metric system. The CGPM still meets at least every six years in Paris and controls the International Bureau of Weights and Measures, which preserves metric standards, compares national standards with them, and conducts research to establish new standards. In 1960, thirty-six countries (including the United States) gave their approval to the SI (Système International de Unités). However, and in spite of all efforts, the United States, Latin America, and Spain do not comply.

\section{Punctuation of Numbers}

According to the SI system

- The recommended decimal marker is a dot on the line. When writing numbers of less than one, a zero should be written before the decimal marker.

- Outside the United States, the comma is often used as a decimal marker.

Therefore, the common practice in the United States of using the comma to separate digits into groups of three (as in 23,478 ) may cause problems.

\begin{tabular}{|c|c|c|}
\hline United States & Europe & Latin America and Spain \\
\hline 2.141596 & 2.141596 & 2,141596 \\
\hline 73,722 & 73722 & 73722 \\
\hline .1335 & 0.1335 & 0,1335 \\
\hline 7,372 & 7372 & 7.372 \\
\hline
\end{tabular}

\begin{tabular}{|l|l|}
\hline Area & Example \\
\hline United States & $\begin{array}{l}\text { While the market stabilizes, you can use our wire reserves: } \\
48,620 \mathrm{lb}, \text { at } 95 \% \text { purity, refined through electrolytic processes } \\
\text { and prepared in rolls of 110.5 lb to 22.1 lb and at a thickness of } \\
0.032 \text { in. and .044 in. in diameter. }\end{array}$ \\
\hline Europe & $\begin{array}{l}\text { While the market stabilizes, you can use our wire reserves: } \\
\text { 22 000 kilograms, at 95\% purity, refined through electrolytic } \\
\text { processes and prepared in rolls of 50 to 100 kilograms and at a } \\
\text { thickness of 0.80 and 1.10 millimeters in diameter. }\end{array}$ \\
\hline $\begin{array}{l}\text { Latin America and } \\
\text { Spain }\end{array}$ & $\begin{array}{l}\text { While the market stabilizes, you can use our wire reserves: } \\
\text { 22.000 kilograms, at 95\% purity, refined through electrolytic } \\
\text { processes and prepared in rolls of 50 to 100 kilograms and at a } \\
\text { thickness of 0,80 and 1,10 millimeters in diameter. }\end{array}$ \\
\hline
\end{tabular}


Other examples are

\begin{tabular}{|l|l|}
\hline Area & Example \\
\hline United States & $\begin{array}{l}\text { The minimum effective heat-transfer area of the new reservoir } \\
\text { was estimated to be about } 480,000 \mathrm{ft}^{2} .\end{array}$ \\
\hline Europe & $\begin{array}{l}\text { The minimum effective heat-transfer area of the new reservoir } \\
\text { was estimated to be about } 45000 \mathrm{~m}^{2} .\end{array}$ \\
\hline Latin America/Spain & $\begin{array}{l}\text { The minimum effective heat-transfer area of the new reservoir } \\
\text { was estimated to be about } 45.000 \mathrm{~m}^{2} .\end{array}$ \\
\hline
\end{tabular}

\begin{tabular}{|l|l|}
\hline Area & Example \\
\hline United States & $10,000, \$ 1.50$ \\
\hline Europe & 10000 \\
\hline $\begin{array}{l}\text { Latin America and } \\
\text { Spain }\end{array}$ & $10.000,1,50$ pesetas \\
\hline
\end{tabular}

In SI notation, the preferred method is to use only numbers between 0.1 and 1,000 . In other words, instead of writing $10,000 \mathrm{~m}$, one would write $10 \mathrm{~km}$.

The comma serves as the decimal point, and periods or spaces are used to group the digits of large numbers. ${ }^{13}$

\begin{tabular}{|l|l|}
\hline Area & Example \\
\hline United States & $1,000,523$ or $47,938.275$ \\
\hline European & 1.000 .523 or 47938,275 \\
\hline
\end{tabular}

\section{Further examples}

\begin{tabular}{|l|l|}
\hline Rule (Latin America or Spain) & Example \\
\hline $\begin{array}{l}\text { 1. A single digit remaining after three } \\
\text { numbers to the right of the decimal point is } \\
\text { added to the final group. }\end{array}$ & 1,5274304 \\
\hline 2. Spaces indicate thousands. & $\begin{array}{l}\text { The maximum distance of the sun from the } \\
\text { planet Uranus is 3 005 000 000 km or } \\
\text { 20,10 times the distance to the Earth. }{ }^{14}\end{array}$ \\
\hline 3. Commas are used for decimals & $\begin{array}{l}\text { (a) W is the symbol for watt, or 0,000 000 } \\
\text { 01 erg per second. } \\
\text { (b) Are you still using the measurements of } \\
2,44 \times 1,22 \text {. }^{12}\end{array}$ \\
\hline
\end{tabular}

\section{Units of Measure}

The SI consists of seven base units, two supplementary units, over fifty derived units (units expressed algebraically in terms of the base or supplementary units, and some "other" units (units so widely used that they are accepted even though not strictly part of the SI. Examples are liter, minute, hour, bar, curie, and angstrom). These units are intended to allow expression of most physicochemical measurements. The seven base units are 


\begin{tabular}{|c|c|}
\hline Unit & Symbol \\
\hline meter (length) & $\mathrm{m}$ \\
\hline kilogram (mass) & $\mathrm{kg}$ \\
\hline second (time) & $\mathrm{s}$ \\
\hline $\begin{array}{c}\text { ampere (electric current) } \\
\text { entim (thermodynamic } \\
\text { temperature) }\end{array}$ & $\mathrm{A}$ \\
\hline $\begin{array}{c}\text { mole (amount of } \\
\text { substance) }\end{array}$ & $\mathrm{mol}$ \\
\hline $\begin{array}{c}\text { candela (luminous } \\
\text { intensity) }\end{array}$ & $\mathrm{cd}$ \\
\hline
\end{tabular}

The two supplementary units are the radian (rad) and the steradian (sr) for plane and solid angles. The great advantage of the SI is that one and only one unit is used is for each physical quantity. Units beyond the elemental ones are derived by simple equations.

\section{Usage}

Billion means a thousand million (prefix giga) in the United States, but a billion means a million million (prefix tera) in most other countries. The terms billion and trillion should be avoided in technical writing.

This is true in Latin America as well. In the Pequeño Larousse, ${ }^{14}$ "un billon" (a billion) is defined as a million millions. However, the editor observes that "in some parts, especially in the U.S., a billion persists in the meaning of a thousand millions, which is contrary to etymology (the history of words) and causes no few errors in relations with other nations."

The Oxford Advanced Learner's Dictionary ${ }^{15}$ states that a billion was "formerly" the number 1000000000000 (a million million) in Britain. Now it is a thousand million-1 00000000 . So apparently only the U.S. persists in this misconception.

Britain uses both metric and nonmetric systems for measurement. However, Britain always uses the metric system in a scientific context. ${ }^{15}$

\begin{tabular}{|l|l|}
\hline Examples & Great Britain \\
\hline 1. & $\begin{array}{l}\text { The road rises to } 5250 \mathrm{~m} \text { above sea level. } \\
\text { The ice is several centimeters thick. } \\
\text { The rope is } 5 \text { feet long. }\end{array}$ \\
\hline 2. & A person is 1.63 metres tall or five feet four inches tall. \\
\hline 3. & It is 35 miles to London. \\
\hline
\end{tabular}




\section{Spelling of Terms of Measurement}

\begin{tabular}{|c|c|}
\hline Variants of per thousand or $10^{-5}$ & Source \\
\hline Per mille & $\begin{array}{l}\text { McGraw Hill's Dictionary of Scientific } \\
\text { Terms }{ }^{16 *} \\
\text { Webster's Third New International } \\
\text { Dictionary }^{17}\end{array}$ \\
\hline Permille & $\begin{array}{l}\text { Webster's Third New International } \\
\text { Dictionary }{ }^{17}\end{array}$ \\
\hline Per mil & $\begin{array}{l}\text { Webster's Third New International } \\
\text { Dictionary }{ }^{17}\end{array}$ \\
\hline Permil & $\begin{array}{l}\text { The Elements on Earth, Inorganic } \\
\text { Chemistry in the Environment }{ }^{18}\end{array}$ \\
\hline Per mill & $\begin{array}{l}\text { Webster's Third New International } \\
\text { Dictionary } \\
\text { Power-generation context (parts per } \\
\text { thousand of a dollar as in mill levy, } \\
\text { mills/kWhe) }\end{array}$ \\
\hline$\%$ & Symbol for concept \\
\hline
\end{tabular}

*Los Alamos National Laboratory standard.

\section{Conclusion}

Both editors and authors should be aware of the differences in technical usage by Europeans and Latin Americans. In a global economy, it is very important that these units be written differently because even after many centuries, we still do not have one standard. 


\section{Acknowledgments}

We would like to thank the efforts of the many people who contributed to this manual from its very beginning some 14 years ago. We began with brainstorming, and the following people were on the original planning committee: Maco Stewart, Helen Sinoradski, Carol Wade, Amy Longshore, Maria DiStravolo, and Dorothy Amsden.

The committee has changed over time with new editors taking over for those that have left the group or the Laboratory. Thanks to these people for their input and assistance as well: Pat Wing, Cynthia Phillips, Doris Gula, and Ann Mauzy. 



\section{REFERENCES}

1. Makkai, A Dictionary of American Idioms, $2^{\text {nd }}$ Edition (Barrons, New York, 1987).

2. American Heritage Dictionary of the English Language, Fourth Edition (Houghton Mifflin Company, New York, 2000).

3. The ACS Style Guide, A Manual for Authors and Editors, Janet S. Dodd, Ed. (American Chemical Society, Washington D.C., 1997).

4. "How Do They Do It? Revisions," The Editorial Eye, August 1999, pp. 7 and 12.

5. Campbell, Elaine, ESL Resource Book for Engineers and Scientists (John Wiley \& Sons, Inc., New York, 1995).

6. Style: Ten Lessons in Clarity and Grace, Third Edition, Joseph M. Williams, Ed. (Harper Collins Publishers, University of Chicago, 1981).

7. Crews, Frederick, The Random House Handbook, Fifth Edition (McGraw Hill Publishing Company, New York, 1987).

8. Fernald, James G., Rev. by Cedric Gale, English Grammar Simplified, Revised Edition, (Barnes \& Noble 1979).

9. O'Connor, Patricia T., Woe is I (Grossett, Putnam's, New York, 1996).

10. Parade Magazine, "Marilyn's World Records," August 25, 1996.

11. Standard Practice for Use of the SI International System of Units, The Modernized Metric System, American Society for Testing and Materials document ASTM E 38093 (1993).

12. García Martín, José Carlos, Correspondencia Comercial (HARLA, S.A. de C.V., México, 1973.)

13. Style Manual Committee, Council of Biology Editors, Scientific Style and Format, The CBE Manual for Authors, Editors, and Publishers, $6^{\text {th }}$ Ed. (Cambridge University Press, UK, 1994).

14. De Galiana Mingot, Tomás, Pequeño Larousse de Ciencias y Técnicas, (Ediciones Larousse, México, D.F., 1984).

15. Hornby, A.S., Oxford Advanced Learner's Dictionary of Current English, Fifth Edition (Oxford University Press, Oxford, England, 1995).

16. Parker, Sybil P., McGraw Hill's Dictionary of Scientific and Technical Terms (Fifth Edition) (McGraw-Hill, Inc., New York, 1994).

17. Webster's Third New International Dictionary, Philip Babcock Gove, Ed., (G. and C. Merriam Company, Springfield, Massachusetts, 1976). 
18. Cox, P.A., The Elements on Earth, Inorganic Chemistry in the Environment (Oxford University Press, Oxford, England, 1995). 